\title{
FINANCIAL BOOTSTRAPPING DAN KINERJA UMKM: PERAN MODERASI LITERASI KEUANGAN
}

\section{Chintya Wira Dika, Maria Rio Rita, dan Imanuel Madea Sakti}

\author{
Fakultas Ekonomika dan Bisnis Universitas Kristen Satya Wacana, Jl. Diponegoro 52-60, \\ Salatiga, 50711, Indonesia. \\ Email: imanuel.sakti@uksw.edu
}

\begin{abstract}
ABSTRAK
Permasalahan klasik yang dialami oleh UMKM adalah keterbatasan akses dana dari perbankan. Hal ini membuat para pelaku UMKM untuk mencari strategi pendanaan alternatif, salah satunya melalui financial bootstrapping. Penelitian ini bertujuan untuk menguji pengaruh financial bootstrapping terhadap kinerja UMKM dengan literasi keuangan sebagai pemoderasi. Sampel penelitian adalah 38 pemilik UMKM di Kota Salatiga yang diuji dengan Moderated Regression Analysis (MRA). Hasil menunjukkan bahwa financial bootstrapping berpengaruh negatif terhadap kinerja UMKM dan peran moderasi literasi keuangan terbukti. Hal ini berarti ketika financial bootstrapping didukung dengan literasi keuangan dari pelaku usaha, maka kinerja usaha akan meningkat.
\end{abstract}

Kata kunci: Financial Bootstrapping, Kinerja UMKM, Literasi Keuangan

\section{ABSTRACT}

The classic problem faced by MSMEs is limited access to funds from banks. This makes MSMEs to look for alternative strategy, one of which is through financial bootstrapping. This study aimed to examine the effect of financial bootstrapping on the performance of MSMEs with financial literacy as a moderator. The research sample were 38 MSME owners in Salatiga City, which were tested by Moderated Regression Analysis (MRA). The results showed that financial bootstrapping had a negative effect on the performance of MSMEs and the moderating role of financial literacy were proven. This means that when financial bootstrapping is supported by financial literacy from business actors, business performance will increase.

Key words: Financial Bootstrapping, Financial Literacy, MSMEs Performance

\section{PENDAHULUAN}

Di Indonesia, jumlah Usaha Mikro Kecil dan Menengah (UMKM) mengalami peningkatan dari tahun ke tahun sehingga berdampak positif ke Produk Domestik Bruto (PDB) Indonesia. Hartomo (2019), menyatakan bahwa UMKM memberikan kontribusi terhadap PDB 
Indonesia sebesar Rp 8.400 triliun di tahun 2019 atau setara dengan 60 persen dari $\operatorname{Rp} 14.000$ triliun PDB Indonesia tahun 2018. Adanya peningkatan jumlah UMKM dari tahun ke tahun, tidak berarti bahwa UMKM terbebas dari permasalahanpermasalahan yang dihadapi. Dalam mendirikan dan mengembangkan bisnisnya pelaku UMKM masih kesulitan dalam mengakses modal ke perbankan. Menurut Putra (2018), menjelaskan bahwa dari total jumlah UMKM sebanyak 62,9 juta hanya 20 persen sudah bankable dan sisanya belum bankable. Widiastuti dan Rita (2017), menyatakan hal tersebut dikarenakan perbankan menetapkan persyaratan yang dikenal dengan prinsip "The Five C of Credits" yang artinya yaitu character, capital, collateral, capacity of repayment, dan condition of economic dalam pemberian kredit. Dari kelima prinsip tersebut, UMKM belum mampu memenuhi semua kriteria yang dibuat oleh perbankan sehingga pelaku UMKM sulit mengakses sumber dana dari perbankan.

Para pelaku UMKM dapat mengatasi kelangkaan sumber daya seperti memenuhi keuangan eksternal melalui strategi pendanaan kreatif dan tidak konvensional melalui financial bootstrapping (Löfqvist, 2017). Rita (2019) menjelaskan bahwa financial bootstrapping merupakan strategi pembiayaan kreatif dan nonkonvensional oleh pelaku UMKM untuk mengurangi ketergantungan pada sumber pendanaan eksternal. Menurut Efrata dan Herdinata (2012), terdapat keuntungan dalam menggunakan metode sumber dana alternatif, antara lain: mudah untuk didapatkan, persyaratan yang minimal, tidak diperlukan rencana bisnis yang terlalu detail, serta tidak memerlukan jaminan pinjaman sehingga beberapa UMKM di Surabaya telah menerapkan metode financial bootstrapping. Dengan menggunakan financial bootstrapping, para pelaku usaha dapat meningkatkan penjualan serta omzet sehingga berdampak baik ke kinerja usaha (Jones dan Jayawarna, 2010).

Permasalahan yang dihadapi oleh UMKM tak hanya terbatasnya akses modal formal saja namun juga rendahnya tingkat mengelola keuangan yang dimiliki oleh para pelaku UMKM (Sari, 2016). Dahmen dan Rodríguez (2014) menyatakan bahwa para pelaku UMKM perlu pemahaman tentang literasi keuangan untuk dapat melakukan penyusunan laporan keuangan serta pengelolaan keuangan yang tepat sehingga memungkinkan UMKM mengalami pertumbuhan bisnis.

Penelitian sebelumnya mengenai pengaruh metode bootstrapping terhadap kinerja dilakukan oleh Jones dan Jayawarna (2010) dan Vanacker et al. (2011) yang menunjukkan bahwa terdapat pengaruh positif. Sebaliknya, Rutherford et al. (2012), menyatakan bahwa antara bootstrapping terhadap kinerja perusahaan memiliki pengaruh negatif. Sedangkan terkait dengan hubungan antara literasi keuangan dan kinerja UMKM, Rakhmawati (2018), menyatakan bahwa semakin tinggi tingkat literasi keuangan pada UMKM maka akan diikuti oleh kinerja UMKM yang semakin tinggi. Lebih lanjut, Sindani (2019), mengungkapkan bahwa peran literasi keuangan terbukti dapat 
memoderasi hubungan antara praktik manajemen piutang usaha dan pertumbuhan UMKM di Kenya.

Penelitian ini bertujuan untuk menguji peran literasi keuangan sebagai pemoderasi antara pengaruh financial bootstrapping terhadap kinerja UMKM di Kota Salatiga. Penelitian terkait financial bootstrapping dengan melibatkan literasi keuangan masih relatif terbatasnya. Selain itu, penelitian ini diharapkan dapat memperluas perspektif kajian mengenai entrepreneurial finance, khususnya dalam hal pendanaan alternatif dan kreatif bagi pengembangan usaha UMKM.

\section{METODE}

Penelitian ini menggunakan data primer yang diperoleh dengan menyebarkan kuesioner kepada objek penelitian yaitu UMKM di Kota Salatiga. Populasi penelitian ini berdasarkan data pada Dinas Koperasi dan UKM Kota Salatiga tahun 2019 yaitu sebanyak 93 usaha binaan yang tersebar di empat kecamatan (Kec. Sidorejo, Kec. Sidomukti, Kec. Tingkir, dan Kec. Argomulyo). Metode purposive sampling digunakan sebagai teknik pengambilan sampel pada penelitian ini. Kriteria pemilihan sampel adalah sektor usaha yang memiliki usia $\geq 5$ tahun. Hal ini dikarenakan usaha yang telah melewati 5-10 tahun dianggap telah sukses (Davidsson et al., 2010). Kriteria selanjutnya adalah responden yang melakukan pengisian kuesioner adalah pemilik usaha itu sendiri atau orang yang benar-benar mengerti tentang pendanaan usahanya. Berdasarkan hasil penyebaran kuesioner online melalui aplikasi WhatApps, diperoleh sampel akhir sebanyak 38 unit usaha.

Variabel yang digunakan dalam penelitian ini adalah variabel dependen financial bootstrapping (FB), variabel independen kinerja UMKM $(\mathrm{KU})$, dan variabel moderasi literasi keuangan (LK). Jawaban kuesioner diukur menggunakan skala likert, yaitu skor 1 sampai dengan 5 untuk masing-masing jawaban "sangat tidak setuju" sampai dengan "sangat setuju". Pemberian skor (kuantifikasi) pada kategori jawaban responden ini untuk mentransformasi skala pengukuran data dari ordinal menjadi skala interval. Jadi, transformasi data dapat digunakan untuk merubah data ordinal menjadi interval dengan menghitung skor (nilai hasil transformasi) untuk setiap kategori (Monika et al., 2013).

Teknik analisis dalam penelitian ini menggunakan Moderated Regression Analysis (MRA) dengan program statistik SPSS 23 untuk menguji peran pemoderasi dari literasi keuangan.

\section{HASIL DAN PEMBAHASAN}

Sebelum melakukan pengujian utama, penelitian ini melakukan uji validitas dan reliabilitas pada kuesioner yang digunakan dan uji asumsi klasik. Hasil uji validitas dan reliabilitas menunjukkan bahwa seluruh item pertanyaan kuesioner dinyatakan valid dan reliabel. Selain itu, hasil uji asumsi klasik juga menunjukkan bahwa data berdistribusi normal dan variabel yang digunakan memenuhi asumsi uji linieritas, multikolinieritas, dan 
heterokedastisitas. Hasil pengujian utama ditunjukkan oleh Tabel 1 sebagai berikut:

Tabel 1. Pengujian Hipotesis

\begin{tabular}{lcc}
\hline \multirow{2}{*}{ Variabel } & \multicolumn{2}{c}{ KU } \\
\cline { 2 - 3 } FB & $-0,014^{* *}$ & $\mathbf{( 2 )}$ \\
& $(-0,156)$ & $\left(-0,577^{* *}\right.$ \\
LK & $0,928^{* *}$ & $0,467^{* *}$ \\
& $(4,605)$ & $(0,543)$ \\
FB*LK & & $0,011^{* *}$ \\
& & $(0,552)$ \\
Konstanta & $-0,659^{* * *}$ & $14,987^{* * *}$ \\
& $(-0,119)$ & $(0,519)$ \\
F & 14,903 & 9,840 \\
Sig. F & 0,000 & 0,000 \\
R-sq & 0,460 & 0,465 \\
Adj. R Sq & 0,429 & 0,417 \\
\hline Catatan: ****** secara & berurutan adalah
\end{tabular}

Catatan: ***,*** secara berurutan adalah tingkat signifikansi $\alpha=1 \%, 5 \%, 10 \%$.

Angka di dalam kurung adalah nilai t-hitung. Sumber: Data primer diolah (2020)

Berdasarkan hasil pengujian, hipotesis $\mathrm{H}_{1}$ yang menyatakan bahwa financial bootstrapping berpengaruh terhadap kinerja UMKM diterima. Hal ini dilihat dari nilai signifikansi financial bootstrapping sebesar $0,000<0,05$ dengan koefisien sebesar 0,377 . Hasil ini menyatakan bahwa financial bootstrapping berpengaruh negatif terhadap kinerja UMKM. Hasil lain menunjukkan bahwa variabel literatur keuangan secara konsisten berpengaruh positif terhadap kinerja UMKM dengan tingkat signifikansi di bawah 0,05. Hasil ini menunjukkan bahwa literatur keuangan dapat meningkatkan kinerja UMKM.

Selanjutnya, hipotesis $\mathrm{H}_{2}$ yang menyatakan bahwa literasi keuangan memoderasi pengaruh financial bootstrapping terhadap kinerja UMKM diterima. Hal ini dapat dilihat dari variabel $\mathrm{FB}^{\star} \mathrm{LK}$ (interaksi antara financial bootstrapping dan literasi keuangan) yang memiliki nilai signifikansi lebih kecil dari a $(0,000<0,05)$ dengan koefisien sebesar positif 0,011 . Hal ini mengindikasikan bahwa literasi keuangan memperlemah pengaruh negatif financial bootstrapping terhadap kinerja UMKM. Adanya literasi keuangan dapat mendorong peran financial bootstrapping dalam meningkatkan kinerja UMKM.

Terakhir, nilai Adjusted R-square menunjukkan bahwa kinerja keuangan dapat dijelaskan oleh variabel financial bootstrapping dan literatur keuangan sebesar 41,7-42,9 persen. Sedangkan sisanya dijelaskan oleh variabel lain di luar model penelitian.

\section{Pengaruh Financial Bootstrapping terhadap Kinerja UMKM}

Hasil penelitian menunjukkan bahwa variabel financial bootstrapping berpengaruh terhadap kinerja UMKM ( $\mathrm{H}_{1}$ diterima), lebih lanjut pengaruh yang ditemukan adalah negatif. Hal ini mengindikasikan bahwa penerapan metode financial bootstrapping akan diikuti dengan penurunan kinerja UMKM. Penelitian ini sejalan dengan penelitian yang dilakukan oleh Rutherford et al. (2012) yang menyatakan bahwa metode financial bootstrapping berpengaruh negatif terhadap kinerja atau kelangsungan hidup perusahaan. Hal ini disebabkan karena perusahaan memiliki pendanaan internal yang masih kurang memadai sehingga metode financial 
bootstrapping akan membatasi kinerja dan meningkatkan kegagalan perusahaan.

Penelitian ini sejalan dengan pandangan bahwa para pelaku UMKM menggunakan pendanaan alternatif financial bootstrapping akan berdampak ke kinerja usahanya yang menurun, hal ini dikarenakan pembiayaan internal belum cukup memadai untuk menunjang kegiatan operasionalnya. Tak hanya itu, ketika pelaku UMKM menggunakan financial bootstrapping yang tidak diimbangi dengan pemanfaatan dan pengelolaan keuangan dengan tepat maka akan menyebabkan kinerja usaha stagnan atau justru mengalami penurunan. Namun, ketika financial bootstrapping ditunjang dengan literasi keuangan yang dimiliki oleh pelaku usaha, maka akan berdampak pada peningkatan kinerja usahanya. Hal ini dikarenakan pelaku usaha dapat mengelola usaha maupun keuangannya dengan baik.

Dahmen dan Rodríguez (2014), menyatakan bahwa ketika pengelolaan keuangan UMKM untuk kegiatan produksi tidak terkelola dengan baik, maka secara tidak langsung akan terjadi penurunan kinerja usaha. Faktor lain yang diduga menyebabkan financial bootstrapping berpengaruh negatif terhadap kinerja UMKM adalah bahwa UMKM masih belum mengerti disiplin administrasi. Pelaku UMKM tak tahu bagaimana cara membuat laporan keuangan serta masih mencampuradukkan antara keuangan usaha dan keuangan rumah tangga sehingga usaha yang dijalankan tidak tumbuh melainkan stagnan. Sabila dan Wijayangka (2019), menjelaskan bahwa pelaku UMKM dengan tingkat literasi yang rendah tidak tahu bagaimana mengelola keuangan dengan baik dan mencampurkan antara pengeluaran usaha dengan pengeluaran pribadinya, tentu hal ini berdampak pada usaha yang dijalankan akan stagnan dan tidak mengalami pertumbuhan.

\section{Literasi Keuangan Memoderasi Pengaruh Financial Bootstrapping terhadap Kinerja UMKM}

Hasil penelitian menunjukkan bahwa keberadaan literasi keuangan memoderasi pengaruh financial bootstrapping terhadap kinerja UMKM $\left(\mathrm{H}_{2}\right.$ diterima). Adanya interaksi antara financial bootstrapping dengan literasi keuangan menyebabkan kinerja UMKM meningkat. Literasi keuangan dapat memperbaiki pengaruh negatif financial bootstrapping sebelumnya. Pelaku usaha dengan literasi keuangan yang baik dapat menggunakan metode financial bootstrapping untuk meningkatkan kinerja usahanya.

Penelitian ini sejalan dengan Adomako et al. (2015), bahwa literasi keuangan yang berperan sebagai pemoderasi dapat meningkatkan pertumbuhan UMKM di Ghana. Hal ini dikarenakan adanya literasi keuangan dapat membantu pelaku UMKM untuk menerapkan keterampilan manajemen keuangan yang baik serta mengeksploitasi pengetahuan keuangan yang baru untuk meningkatkan efisiensi dalam peningkatan pertumbuhan UMKM.

Hasil ini sesuai dengan pandangan bahwa apabila tingkat 
literasi keuangan pelaku usaha tinggi, maka pelaku usaha dapat mengelola sumber pendanaan melalui financial bootstrapping secara baik sehingga dapat memposisikan peningkatan kinerja usaha. Latar belakang pendidikan terakhir dan umur usaha juga diduga merupakan faktor yang memperkuat moderasi literasi keuangan terhadap financial bootstrapping dan kinerja UMKM di Kota Salatiga. Ningrum (2018), menyatakan bahwa setiap individu akan memiliki tingkat pengetahuan keuangan yang lebih tinggi sehingga dapat mengelola keuangan dengan tepat jika tingkat pendidikannya di atas wajib belajar dibandingkan dengan individu yang memiliki tingkat pendidikan di bawah wajib belajar.

\section{Berdasarkan}

karakteristik responden dalam penelitian ini, mayoritas pelaku UMKM di Kota Salatiga memiliki pendidikan terakhir yaitu tingkat SMA/SMK. Hal ini membuktikan bahwa pelaku UMKM di Kota Salatiga sudah mengetahui tentang pengetahuan keuangan maupun lembaga keuangan. Dengan demikian, pelaku UMKM mampu mengelola keuangan secara tepat agar terhindar dari risiko keuangan.

Selanjutnya, terkait dengan umur usaha, karakteristik responden menunjukkan bahwa umur usaha yang dijalankan sudah di atas 5 tahun. Hal ini mengindikasikan bahwa pelaku usaha tersebut sudah mampu untuk mengelola usahanya dengan baik dan dapat bertahan dari goncangan awal usaha sehingga selanjutnya dapat memiliki kinerja positif.

\section{KESIMPULAN}

Hasil penelitian dapat disimpulkan sebagai berikut:

1. Financial bootstrapping berpengaruh negatif terhadap kinerja UMKM.

2. Literasi keuangan memoderasi hubungan antara financial bootstrapping dan kinerja UMKM.

3. Literasi keuangan akan mendorong pelaku usaha dalam penggunaan financial bootstrapping guna meningkatkan kinerja usaha UMKM.

Temuan ini diharapkan dapat mendorong pelaku UMKM untuk meningkatkan literasi keuangannya. Dengan demikian, pelaku usaha dapat mengelola keuangan secara lebih baik sehingga meningkatkan kinerja usahanya.

\section{DAFTAR PUSTAKA}

Adomako, S., Danso, A., \& Ofori Damoah, J. (2015). The Moderating Influence of Financial Literacy on The Relationship Between Access to Finance and Firm Growth in Ghana. Venture Capital, 18(1), 4361.

Dahmen, P., \& Rodríguez, E. (2014). Financial Literacy and The Success of Small Businesses: An Observation from a Small Business Development Center. International Journal of Numeracy, 7(1), 1-2.

Davidsson, P., Achtenhagen, L., \& Naldi, L. (2010). Small Firm Growth. Foundations and Trends in Entrepreneurship, 6(2), 69-166.

Efrata, T. C., \& Christian Herdinata. (2012). Penerapan Metode 
Bootstrap Financing Pada Usaha Kecil Dan Menengah di Surabaya. Keuangan Dan Perbankan, 16(3), 399-406.

Hartomo, G. (2019). UMKM Sumbang Rp 8.400 Triliun ke Perekonomian Nasional Pada 2018. Economy.Okezone.Com. https:/ / economy.okezone.com/ $\mathrm{read} / 2019 / 06 / 19 / 320 / 2068296 /$ umkm-sumbang-rp8-400-triliunke-perekonomian-nasionalpada-2018

Jones, O., \& Jayawarna, D. (2010). Resourcing New Businesses: Social Networks, Bootstrapping and Firm Performance. Venture Capital, 12(2), 127-152.

Löfqvist, L. (2017). Product Innovation in Small: Companies Managing Resource Scarcity Through Financial Bootstrapping. Journal of Innovation Management, 21(2), 127.

Monika, N., Nohe, D. A., \& Sifriyani. (2013). Analisis Chi-square dan Transformasi Data Ordinal ke Data Interval Menggunakan Methods of Succesive Interval ( MSI ) ( Studi Kasus: Siswa Kelas XI SMA Negeri 5 Samarinda ). Jurnal Eksponensial, 4, 85-90.

Ningrum, I. A. (2018). Analisis Faktor Pengaruh Literasi Keuangan terhadap Pelaku UMKM Kota Makassar (Studi Kasus Pasar Sentral). 7, 1-25.

Putra, D. A. (2018). Kemenkop: Baru 20 Persen UMKM yang Mengakses Modal Lewat Bank. Merdeka.Com. https:/ / www.merdeka.com/ua ng/kemenkop-baru-20-persenumkm-yang-mengakses-modallewat-bank.html

Rakhmawati, F. F. (2018). Pengaruh Literasi Keuangan, Penggunaan Informasi Akuntansi dan Sumber Daya Manusia Terhadap Kinerja UKM (Studi Kasus UKM Batik Tulis di Kabupaten Pekalongan). Ekonomi Dan Bisnis, 1-16.

Rita, M. R. (2019). Financial Bootstrapping: External Financing Dependency Alternatives for SMEs. Jurnal Ekonomi Dan Bisnis, 22(1), 83100.

Rutherford, M. W., Coombes, S. M. T., \& Mazzei, M. J. (2012). The Impact of Bootstrapping on New Venture Performance And Survival: A Longitudinal Analysis. Frontiers of Entrepreneurship Research, 32(12), 4.

Sabila, S. O., \& Wijayangka, C. (2019). Pengaruh Literasi Keuangan terhadap Pertumbuhan Usaha Pada UMKM. Jurnal Manajemen Dan Bisnis, 3(1), 145-152.

Sari, E. V. (2016). BI: Tingkat Literasi Keuangan Pelaku UMKM Rendah. Cnnindonesia.Com.

Sindani, M. N. (2019). The Moderating Effect of Financial Literacy on The Relationship Between Accounts Receivable Management Practices and Growth of Smes In Kenya. Expert Journal of Finance, 7(1), 1-7. 
Vanacker, T., Manigart, S., Meuleman, M., \& Sels, L. (2011). A Longitudinal Study on The Relationship Between Financial Bootstrapping and New Venture Growth. Entrepreneurship and Regional Development, 23(9-10), 681-705.

Widiastuti, R., \& Rita, M. R. (2017). Apakah Kredit Usaha Rakyat (KUR) Berdampak Pada Kinerja Usaha?: Studi Pada UMKM Makanan Ringan di Kota Salatiga. Jurnal Visi Manajemen, 2(2), 100-115. 